\title{
Prospective Risk Factors of Toxoplasmosis Seropositivity in Pregnant Women: The Fundamental Role of Community Healthcare Education
}

\author{
Lienda Bashier Eltayeb ${ }^{*}$, Nasir Abdelrafie Hamad ${ }^{2}$, Abeer Abd Alla Ellhassan Babiker ${ }^{1}$ \\ ${ }^{I}$ Department of Medical Laboratory Sciences, College of Applied Medical Sciences, \\ Prince Sattam Bin AbdulAziz University-Al-Kharj, Riyadh, KSA \\ ${ }^{2}$ Department of Biochemistry, Faculty of Medicine, National University of Sciences and Technology, Oman
}

\begin{abstract}
Background: The present study conducted a survey on awareness of toxoplasmosis infection, with an emphasis on risk factors, and an assessment of toxoplasmosis prevalence in pregnant women in Al-Kharj province of KSA.

Methods and Results: A cross-sectional study with a qualitative approach was carried out from August 2018 to February 2019. The study recruited all pregnant women who attended maternity and children's outpatient clinics. The non-probability sampling approach was used to select 345 blood samples from study subjects. T. gondii-specific IgG and IgM antibodies were identified using ELISA. ach participant enrolled in the study was provided with a validated questionnaire to fill out by an assistant of the laboratory technician or an antenatal care nurse. In addition to socio-demographic data, simple closed-ended questions about established risk factors for $T$. gondii exposure were included in the questionnaire items, and answers were listed in a three-point Likert scale (agree, disagree, I am not sure). The overall prevalence of T. gondii-specific antibodies among study subjects was $12.75 \% ; 29(8.40 \%)$ women were positive for IgG only, $9(2.6 \%)$ - for IgM, and 6(1.7\%) - for both IgG and IgM antibodies. About $41.4 \%$ of participants were in the first trimester of pregnancy; among them 31(9\%) were positive for T. gondii antibodies. $82.8 \%$ of pregnant women had chronic infection in the first trimester, while $44.4 \%$ of those women also had an acute infection. The number of respondents to the questionnaire was 345 participants with a response rate of about $100 \%$. It is important to note that $81.5 \%$ of women were unaware that toxoplasmosis is dangerous, and two-thirds of them didn't know the dangerous complications for the fetus and newborn.

Conclusion: The current study concludes that there is a low prevalence of toxoplasmosis among Saudi pregnant women in Al-Kharj province. A general program must be implemented to increase population awareness, especially among the at-risk populations. (International Journal of Biomedicine. 2021;11(4):558-563.)
\end{abstract}

Key Words: Toxoplasma gondii $\bullet$ risk factors $\bullet \operatorname{IgG} \bullet \operatorname{IgM} \bullet$ pregnancy

For citation: Eltayeb LB, Hamad NA, Babiker AAAE. Prospective Risk Factors of Toxoplasmosis Seropositivity in Pregnant Women: The Fundamental Role of Community Healthcare Education. International Journal of Biomedicine. 2021;11(4):558-563. doi:10.21103/Article11(4)_OA26

\section{Introduction}

Toxoplasmosis is a parasitic infection caused by the intracellular protozoan Toxoplasma gondii. ${ }^{(1)} T$. gondii oocysts can infect people through the environment, including in contaminated foods, water, or soil. Pregnant women are at

*Corresponding author: Dr. Lienda Bashier Eltayeb. Department of Medical Laboratory Science, College of Applied Medical Science, Prince Sattam bin Abdulaziz University, Al-Kharj, Saudi Arabia.E-mail: lindarose009@hotmail.com high risk of infection. Acute infections with $T$. gondii during pregnancy and their potentially tragic outcomes for the fetus and newborn continue to occur worldwide. ${ }^{(2,3)}$ Our understanding of the biological life cycle and clinical significance of $T$. gondii has grown throughout the last four decades. $T$. gondii was identified more than a century ago, and it was first identified as a pathogen responsible for congenital infection, although its clinical manifestation and the significance of reactivations of infectious agents in people with compromised immune systems were identified subsequently, specifically in the area of organ transplantation and HIV infection. Current observations about 
the relationships between host cell and parasite, as well as parasite virulence, have added to our knowledge of infection pathophysiology. ${ }^{(4)}$

Most immunocompetent individuals who contract the parasite do not develop symptoms, or might experience nonspecific flulike symptoms. ${ }^{(5-8)}$ However, when $T$. gondii infection is acquired in pregnancy, the parasite can be transmitted across the placenta to the fetus, resulting in congenital toxoplasmosis, which can have grave consequences. ${ }^{(9)}$ Infection during pregnancy can cause severe disease in the fetus (hydrocephalus, intra-cerebral calcification, retinochoroiditis, and mental retardation). ${ }^{(10)}$

Initial maternal serological screening relies on detecting $\operatorname{IgM}$ and $\operatorname{IgG}$ antibodies using an enzyme-linked immunosorbent assay (ELISA). The presence of elevated levels of $T$. gondii-specific IgG antibodies indicates infection has occurred at some point but does not distinguish between an infection acquired recently and one acquired in the distant past. The presence of a high $T$. gondii-specific IgM titer combined with a high $\operatorname{IgG}$ titer probably indicates an acute infection within the previous 3 months. A low-to-medium IgM titer and a high IgG titer might indicate an acute infection 3-6 months previously, but IgM antibodies have been detected as long as 18 months after initial infection. ${ }^{(11-15)}$

The onset of acute toxoplasmosis in pregnant women may pose a risk to their growing fetuses. The timely diagnosis of infection in managing the disease and preventing its harmful consequences on the fetus is very important. ${ }^{(16)}$ Systematic serological screening for $T$. gondii-specific IgG and $\operatorname{IgM}$ antibodies in all pregnant women as early in gestation as feasible (ideally during the first trimester) and in seronegative women each month or trimester thereafter would be optimal. A positive Toxoplasma IgM test is often considered a marker of an acute infection. However, IgM can persist from several months to years after an acute infection, thus making the distinction between an acute and a chronic infection challenging. ${ }^{(16-19)}$

Ultrasonography and PCR with amniotic fluid are being used predominantly in the prenatal diagnosis of congenital toxoplasmosis. ${ }^{(20,21)}$ Pregnancy, direct contact with a cat, soil contact, consumption of undercooked meat, and drinking unpasteurized milk, as well as sources of drinking water, are considered as significant risk factors for acquiring toxoplasmosis. ${ }^{(10,21)}$ Numerous pregnant women, nevertheless, are unaware of such risk factors. The present study conducted a survey on awareness of toxoplasmosis infection, with an emphasis on risk factors, and an assessment of toxoplasmosis prevalence in pregnant women in Al-Kharj province of KSA.

\section{Materials and Methods}

A cross-sectional study with a qualitative approach was carried out from August 2018 to February 2019. The study recruited all pregnant women who attended maternity and children's outpatient clinics. The study was performed in AlKharj province, with a population of 332,243, in 2017.

The non-probability sampling approach was used to select 345 blood samples from study subjects. Samples were centrifuged to separate serum and preserved at $20^{\circ} \mathrm{C}$ for serological examination for one week. T. gondii-specific IgG and IgM antibodies were identified using ELISA, a commercial kit (Biokit-Bioelisa Toxo IgG/Italy, and Organon-Toxonostika IgM II Mikro ELISA kit), and the manufacturer's guidelines. ${ }^{(22)}$

Each participant enrolled in the study was provided with a validated questionnaire to fill out by an assistant of the laboratory technician or an antenatal care nurse. In addition to socio-demographic data, simple closed-ended questions about established risk factors for T. gondii exposure were included in the questionnaire items, and answers were listed in a threepoint Likert scale (agree, disagree, I am not sure).

Statistical analysis was performed using the IBM SPSS Statistics for Windows, Version 20.0. Armonk, NY: IBM Corp.). Baseline characteristics were summarized as frequencies and percentages for categorical variables. Group comparisons were performed using chi-square tests with Yates correction. A probability value of $P<0.05$ was considered statistically significant.

The study was approved by the Ethics Committee of the department of Medical Laboratory Sciences, Al-Neelain University. Written informed consent was obtained from each research participant.

\section{Results}

A total of 345 blood samples were collected by laboratory staff at Al-Kharj maternity and children's hospital. All pregnant women were screened for toxoplasmosis using ELISA to identify $T$. gondii-specific IgG and IgM antibodies. The overall prevalence of $T$. gondii-specific antibodies among study subjects was $12.75 \% ; 29(8.40 \%)$ women were positive for IgG only, $9(2.6 \%)$ - for IgM, and $6(1.7 \%)$ - for both IgG and IgM antibodies (Tables 1).

Table 1.

T. gondii-specific IgG and IgM antibodies in study blood samples

\begin{tabular}{|c|c|c|}
\hline Antibodies & $\begin{array}{c}\text { Positive } \\
\mathrm{n}(\%)\end{array}$ & $\begin{array}{c}\text { Negative } \\
\mathrm{n}(\%)\end{array}$ \\
\hline $\operatorname{IgG}(+), \operatorname{IgM}(-)$ & $29(8.4)$ & \multirow{2}{*}{$301(87.25)$} \\
\cline { 1 - 2 } $\operatorname{IgG}(-), \operatorname{IgM}(+)$ & $9(2.6)$ & \\
\cline { 1 - 2 } $\operatorname{IgG}(+), \operatorname{IgM}(+)$ & $6(1.7)$ & \\
\hline Total & $44(12.75)$ & \\
\hline
\end{tabular}

The majority of participants (57.7\%) were in the age group of 25-34 years, and among them 25(7.2\%) were positive for $T$. gondii antibodies (Table 2). About $41.4 \%$ of participants were in the first trimester of pregnancy; among them $31(9 \%)$ were positive for $T$. gondii antibodies. The study showed that gestational age, abortion, as well as cat ownership, had a significantly positive correlation with seropositivity of toxoplasmosis. Table 3 and Figure 1 display the frequency of $T$. gondii-specific antibodies related to gestational age: $82.8 \%$ of pregnant women that had chronic infection were in the first trimester, while $44.4 \%$ of those women also had an acute infection. 
Table 2.

Clinical and demographic characteristics of the study population

\begin{tabular}{|c|c|c|c|c|}
\hline Pattern & $\begin{array}{l}\text { Total } \\
\mathrm{n}(\%)\end{array}$ & $\begin{array}{c}\text { Positive } \\
\text { for } T \text {. gondii } \\
\text { antibodies } \\
{[\mathrm{P}]}\end{array}$ & $\begin{array}{c}\text { Negative } \\
\text { for T. gondii } \\
\text { antibodies } \\
{[\mathrm{N}]}\end{array}$ & $\begin{array}{c}P \\
(\mathrm{P}-\mathrm{N})\end{array}$ \\
\hline \multicolumn{5}{|l|}{ Age group, yrs } \\
\hline $15-24$ & $86(24.9)$ & $12(3.5)$ & $74(21.4)$ & \multirow{4}{*}{0.913} \\
\hline $25-34$ & 199(57.7) & $25(7.2)$ & $174(50)$ & \\
\hline 3545 & $60(17.4)$ & $7(2.1)$ & $53(10.1)$ & \\
\hline Total & $345(100)$ & $44(12.8)$ & $301(87.2)$ & \\
\hline \multicolumn{5}{|l|}{ Education } \\
\hline Primary & $113(32.8)$ & $14(4.1)$ & $99(28.7)$ & \multirow{3}{*}{0.981} \\
\hline Secondary & $121(34.8)$ & $16(4.6)$ & $105(30.4)$ & \\
\hline Tertiary & $111(32.2)$ & $14(4.1)$ & $97(28.1)$ & \\
\hline \multicolumn{5}{|l|}{ Gestational age } \\
\hline First trimester & $143(41.4)$ & $31(9)$ & $112(32.5)$ & \multirow{3}{*}{0.000} \\
\hline Second Trimester & $125(36.2)$ & $9(2.6)$ & $116(33.6)$ & \\
\hline Third trimester & $77(22.3)$ & $4(1.2)$ & $73(21.2)$ & \\
\hline \multicolumn{5}{|c|}{ History of abortion } \\
\hline Yes & $59(17.1)$ & $21(6.1)$ & $38(11)$ & \multirow{2}{*}{0.000} \\
\hline No & $286(82.9)$ & $23(6.7)$ & $263(76.2)$ & \\
\hline \multicolumn{5}{|l|}{ Risk factors } \\
\hline \multicolumn{5}{|l|}{ Cat ownership } \\
\hline Yes & $15946.1)$ & $39(11.3)$ & $120(34.8)$ & \multirow{2}{*}{0.000} \\
\hline No & $186(53.9)$ & $5(1.4)$ & $181(52.4)$ & \\
\hline \multicolumn{5}{|l|}{$\underline{\text { Blood transfusion }}$} \\
\hline Yes & $28(8.1)$ & $4(1.2)$ & $24(7.0)$ & \multirow{2}{*}{0.800} \\
\hline No & $317(91.9)$ & $40(11.6)$ & $277(80.2)$ & \\
\hline \multicolumn{5}{|l|}{ Direct soil contact } \\
\hline Yes & $224(65)$ & $19(5.5)$ & $205(50.4)$ & \multirow{2}{*}{0.001} \\
\hline No & $121(35)$ & $25(7.2)$ & $96(27.8)$ & \\
\hline \multicolumn{5}{|c|}{ Consumption of undercooked meat } \\
\hline Yes & $287(83.2)$ & $24(6.9)$ & $263(76.2 \%)$ & \multirow{2}{*}{0.000} \\
\hline No & $58(16.8)$ & $20(5.8)$ & $38(11 \%)$ & \\
\hline
\end{tabular}

Table 3.

The frequency of T. gondii-specific antibodies related to gestational age

\begin{tabular}{|l|c|c|c|c|}
\hline \multicolumn{1}{|c|}{ Parameters } & $\begin{array}{c}\operatorname{IgG}(+) / \operatorname{IgM}(-) \\
\mathrm{n}(\%)\end{array}$ & $\begin{array}{c}\operatorname{IgG}(+) / \operatorname{IgM}(+) \\
\mathrm{n}(\%)\end{array}$ & $\begin{array}{c}\operatorname{IgG}(-) / \operatorname{IgM}(+) \\
\mathrm{n}(\%)\end{array}$ & $P$ \\
\hline $\begin{array}{l}\text { First trimester } \\
(\mathrm{n}=113)\end{array}$ & $24(82.8)$ & $3(50 \%)$ & $4(44.4 \%)$ & 0.000 \\
\hline $\begin{array}{l}\text { Second trimester } \\
(\mathrm{n}=121)\end{array}$ & $2(6.9)$ & $3(50 \%)$ & $4(44.4 \%)$ & 0.880 \\
\hline $\begin{array}{l}\text { Third trimester } \\
(\mathrm{n}=111)\end{array}$ & $3(10.3)$ & 0 & $1(11.1 \%)$ & 0.454 \\
\hline Total & $29(100)$ & $6(100 \%)$ & $9(100 \%)$ & \\
\hline
\end{tabular}

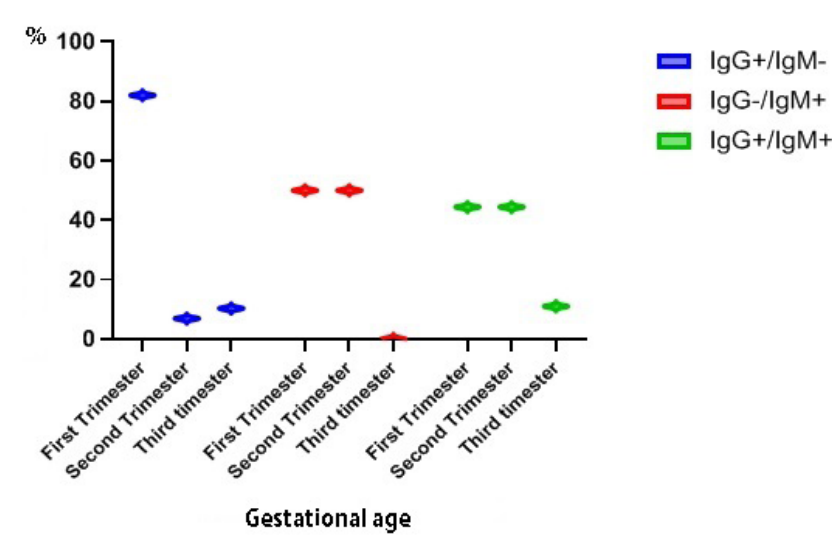

Fig. 1. The frequency of T. gondii-specific antibodies related to gestational age

Table 4 summarized the level of population awareness about toxoplasmosis. The number of respondents to the questionnaire was 345 participants with a response rate of about $100 \%$. When we asked whether participants had heard of $T$. gondii, $50.4 \%$ of respondents answered, "agree." Almost half (49.6\%) of women stated that toxoplasmosis is not a dangerous infection. However, only $35 \%$ agreed that $T$. gondii is transmitted through the eating of poorly washed vegetables and undercooked meat, and $73.6 \%$ agreed that cats are the main host for transmitting infection. Two-thirds of subjects didn't know that blood transfusion may be a source of infection, and only $22.9 \%$ agreed that toxoplasmosis is symptomless.

\section{Table 4}

The level of population awareness about toxoplasmosis

\begin{tabular}{|l|c|c|c|}
\hline \multicolumn{1}{|c|}{ Questions } & $\begin{array}{c}\text { Agree } \\
\mathrm{n}(\%)\end{array}$ & $\begin{array}{c}\text { Disagree } \\
\mathrm{n}(\%)\end{array}$ & $\begin{array}{c}\text { Not sure } \\
\mathrm{n}(\%)\end{array}$ \\
\hline $\begin{array}{l}\text { Do you know toxoplasmosis } \\
\text { infection }\end{array}$ & $174(50.4)$ & $161(46.6)$ & $10(2.9)$ \\
\hline Toxoplasmosis is dangerous & $64(18.6)$ & $171(49.6)$ & $110(31.9)$ \\
\hline It is an infectious disease & $76(22)$ & $23(6.7)$ & $246(71.3)$ \\
\hline $\begin{array}{l}\text { It is transmitted by } \\
\text { improbably washed } \\
\text { vegetables }\end{array}$ & $123(35.7)$ & $98(28.4)$ & $124(35.9)$ \\
\hline $\begin{array}{l}\text { It is transmitted by } \\
\text { eating undercooked meat }\end{array}$ & $124(35.9)$ & $32(9.3)$ & $189(54.8)$ \\
\hline $\begin{array}{l}\text { Cats are a major cause } \\
\text { of transmission of disease }\end{array}$ & $254(73.6)$ & $6(1.5)$ & $85(24.6)$ \\
\hline $\begin{array}{l}\text { It can be transmitted } \\
\text { through blood transfusion }\end{array}$ & $110(31.9)$ & $165(47.8)$ & $70(20.3)$ \\
\hline $\begin{array}{l}\text { Direct contact with soil may } \\
\text { be a source of infection }\end{array}$ & $98(28.4)$ & $119(43.5)$ & $128(37.1)$ \\
\hline $\begin{array}{l}\text { There are no apparent } \\
\text { symptoms in healthy people }\end{array}$ & $79(22.9)$ & $162(47)$ & $104(30.1)$ \\
\hline $\begin{array}{l}\text { It can cause abortion or } \\
\text { stillbirth of a child }\end{array}$ & $131(38)$ & $102(29.6)$ & $112(32.5)$ \\
\hline
\end{tabular}




\section{Discussion}

Toxoplasmosis is a widespread, preventable-but-fatal, devastating infection that primarily affects pregnant women due to their weakened immune systems, and its prevalence varies globally. Early diagnosis in the first months of pregnancy, as well as knowledge of the disease's nature and modes of transmission, will significantly contribute to reducing the frequency of toxoplasmosis and thus the potential risks. Our results showed that the overall prevalence of anti-T. gondii antibodies in serum of pregnant women was $12.8 \%$, which was similar to data reported by Sarah et al., who revealed a prevalence rate of about $8.57 \%$ in the city of Hail. ${ }^{(23)}$ However, our seroprevalence was much higher than that (1.4\%), documented by Mohajab et al. in Jeddah. ${ }^{(24)}$ At the same time, our outcomes were less than the previous studies conducted by Alghamdi et al.. ${ }^{(25)}$ who revealed $32.5 \%$ IgG seroprevalence in Riyadh, Elsafi et al. ${ }^{(26)}$ in Dhahran $-28.5 \%$, and Aqeely et al. ${ }^{(27)}$ in Jazan $-24.1 \%$.

In total, our results were more than the $7.9 \%$ measured for the overall population of China in a survey carried out by China's Ministry of Health, and lower than initially reported in Thailand $(22 \%),{ }^{(28)}$ Taiwan $(31.06 \%),{ }^{(29)}$ and Tanzania $(40.2 \%){ }^{(30)}$ These data imply that the parasitic infection is endemic in the region of study. Such discrepancy could be related to various environmental factors and variation of climates between regions, such as air humidity and increased temperature, that control and favor dissemination and infectivity of $T$. gondii oocyst, as well as other considerations, such as different study populations, design of the study, ethnic groups, diagnostic techniques, sample size, and the lifestyle of recruited study participants.

Interestingly, chronic toxoplasmosis infection was found in $8.4 \%$ of pregnant women; besides this, anti-T.gondii IgG and IgM antibodies were observed in $1.7 \%$ of cases, which is difficult to interpret because $\operatorname{IgG}$ avidity was not conducted in the present study, and specific IgM antibodies can persist for several months or even years post-primary infection. We found acute toxoplasmosis in $2.6 \%$ of study participants. A total of $31(9 \%)$ pregnant women were positive for anti-T.gondii antibodies in the first trimester, and $4(44.4 \%)$ of them were IgM positive. This is a major concern because the effects of toxoplasmosis infection on the fetus are more severe during the first trimester of pregnancy, and there is a possibility of vertical transmission and therefore congenital infection. $\left({ }^{(3)}\right.$ The same outcomes were reported by Aqeely et al. ${ }^{(27)}$

Regarding possible demographic and clinical data, we did not find any statistically significant differences between seropositive subjects according to age and education levels. However, a positive relationship was revealed between abortion and the presence of $T$. gondii-specific antibodies.

We found a strong relationship between $T$. gondii seropositivity and cat ownership, as well as direct contact with soil, and no association with blood transfusion and eating undercooked meat. This is in agreement with different studies implying that cats were indeed a potential risk. ${ }^{(32,33)}$ Other studies, on the other hand, found no correlation between $T$. gondii infection and the existence of cats in the home. . $^{(34,35)}$

It is obvious that the infected women get the infections from the cat, since sporozoites really are not detected on cat fur and are regularly buried in soil with cat feces, and soil contact is ubiquitous and hard to avoid. Other risk factors such as blood transfusion and eating undercooked meat play a critical role in the transmission of toxoplasmosis.

However, we did not find significant correlations of those factors with toxoplasmosis, which may be attributed to the strict precautionary measures and protocol followed in Saudi blood banks for safe blood transfusions ${ }^{(36)}$

The preventive measures mostly depend on the women's knowledge about toxoplasmosis, its transmission, and its origin. Regarding the knowledge of toxoplasmosis among the Saudi population, about $50.4 \%$ of the study subjects said that they know about toxoplasmosis. However, it seems like poor or fake knowledge, because two-thirds of respondents give wrong answers, and there is a lack of knowledge concerning disease symptoms, complications, and prevention. These findings are similar to a study carried out by Obaid et al. ${ }^{(37)}$ in Iraq and disagree with many studies in which awareness of toxoplasmosis was much lower. Low knowledge of toxoplasmosis ${ }^{\left({ }^{(0)}\right.}$ was also reported in Asian countries, such as Malaysia, the Philippines, and Thailand.In Egypt, ${ }^{(38)}$ it was found that only $9.9 \%$ of the studied sample had a good knowledge of toxoplasmosis. Similar results were reported in Tanzania and in Ethiopia, where only $5 \%$ and $5.7 \%$, respectively, of pregnant women had known about the disease. ${ }^{(39,40)}$ This rate difference may be due to the different cultural or socio-demographic factors in each country. ${ }^{(41)}$ Interestingly, an association between toxoplasmosis and cat ownership was noted by $73.6 \%$ of those surveyed, which may explain the low prevalence of toxoplasmosis among Saudi pregnant women in Al-Kharj province. It is important to note that $81.5 \%$ of women were unaware that toxoplasmosis is dangerous, and two-thirds of them didn't know the dangerous complications for the fetus and newborn. With this information, provider- and patient-centered strategies, such as monitoring, surveillance, and awareness programs to instruct pregnant women about $T$. gondii, can be established.

Our results cannot be generalized, since the data were collected from one healthcare facility and a low sample size. Furthermore, the seroconversion window period could not be tested because only one blood sample from each woman was evaluated, without any effort to authenticate such infection using IgG avidity tests or polymerase chain reaction.

\section{Conclusion}

The current study concludes that there is a low prevalence of toxoplasmosis among Saudi pregnant women in Al-Kharj province. We need more studies with large samples size to perfectly determine the exact prevalence and incidence rate of toxoplasmosis. A general program must be implemented to increase population awareness, especially among the at-risk populations.

\section{Acknowledgments}

This publication was supported by the Deanship of Scientific Research at Prince Sattam Bin Abdulaziz University. 
The authors would like to express their deepest gratitude to the Department of Medical Laboratory Sciences, College of Applied Medical Sciences at Prince Sattam bin Abdul-Aziz University, and Al Kharj attended maternity and children's outpatient clinics.

\section{Competing Interests}

The authors declare that they have no competing interests.

\section{References}

1. Zhou JJ, Tao LL. [Seroprevalence and risk factors of Toxoplasma gondii infection among pregnant women in Wuxi region]. Zhongguo Xue Xi Chong Bing Fang Zhi Za Zhi. 2015 Dec;27(6):604-7. [Article in Chinese].

2. Montoya JG, Remington JS. Management of Toxoplasma gondii infection during pregnancy. Clin Infect Dis. 2008 Aug 15;47(4):554-66. doi: 10.1086/590149.

3. Foroutan-Rad M, Khademvatan S, Majidiani H, Aryamand S, Rahim F, Malehi AS. Seroprevalence of Toxoplasma gondii in the Iranian pregnant women: A systematic review and metaanalysis. Acta Trop. 2016 Jun;158:160-169. doi: 10.1016/j. actatropica.2016.03.003.

4. Tarekegn ZS, Dejene H, Addisu A, Dagnachew S. Potential risk factors associated with seropositivity for Toxoplasma gondii among pregnant women and HIV infected individuals in Ethiopia: A systematic review and meta-analysis. PLoS Negl Trop Dis. 2020 Dec 15;14(12):e0008944.

5. Chaudhry SA, Gad N, Koren G. Toxoplasmosis and pregnancy. Can Fam Physician. 2014 Apr;60(4):334-6.

6. Jenum PA, Stray-Pedersen B, Melby KK, Kapperud G, Whitelaw A, Eskild A, et al. Incidence of Toxoplasma gondii infection in 35,940 pregnant women in Norway and pregnancy outcome for infected women. J Clin Microbiol. 1998;36(10):2900-6.

7. Montoya JG, Liesenfeld O. Toxoplasmosis. Lancet. 2004;363(9425):1965-76. doi: 10.1016/S01406736(04)16412-X

8. Saadatnia G, Golkar M. A review on human toxoplasmosis. Scand J Infect Dis. 2012;44(11):805-14. doi: 10.3109/00365548.2012.693197.

9. Kieffer F, Wallon M. Congenital toxoplasmosis. Handb Clin Neurol. 2013;112:1099-101. doi: 10.1016/B978-0-444-529107.00028-3.

10. Elmore SA, Jones JL, Conrad PA, Patton S, Lindsay DS, Dubey JP. Toxoplasma gondii: epidemiology, feline clinical aspects, and prevention. Trends Parasitol. 2010 Apr;26(4):1906. doi: $10.1016 /$ j.pt.2010.01.009.

11. Preventing Congenital Toxoplasmosis-CDC. Available from: https://www.cdc.gov/mmwr/preview/mmwrhtml/ rr4902a5.htm

12. Wilson M, McAuley JB. Toxoplasma. In: Murray P, ed. Manual of clinical microbiology. 7th ed. Washington, DC: ASM Press, 1999:1374-82.

13. Lappalainen M, Hedman K. Serodiagnosis of toxoplasmosis. The impact of measurement of IgG avidity. Ann Ist Super Sanita. 2004;40(1):81-8. PMID: 15269456.

14. Machumi I, Mirambo MM, Ruganuza D, Rambau P, Massinde AN, Kihunrwa A, Mshana SE, Morona D. Factors Associated With Toxoplasma gondii IgG and IgM Antibodies, and Placental Histopathological Changes Among Women With Spontaneous Abortion in Mwanza City, Tanzania. East Afr Health Res J. 2017;1(2):86-94. doi: 10.24248/ EAHRJ-D-16-00408.

15. Sardarian K, Maghsood AH, Farimani M, Hajilooi M, Saidijam M, Ghane ZZ, Mahaki H, Zamani A. Detection of Toxoplasma gondii B1 Gene and IgM in IgG Seropositive Pregnant Women. Clin Lab. 2019 Jan 1;65(1). doi: 10.7754/ Clin.Lab.2018.180425. PMID: 30775900.

16. Rostami A, Riahi SM, Contopoulos-Ioannidis DG, Gamble HR, Fakhri Y, Shiadeh MN, Foroutan M, Behniafar H, Taghipour A, Maldonado YA, Mokdad AH, Gasser RB. Acute Toxoplasma infection in pregnant women worldwide: A systematic review and meta-analysis. PLoS Negl Trop Dis. 2019 Oct 14;13(10):e0007807. doi: 10.1371/journal. pntd.0007807.

17. Dhakal R, Gajurel K, Pomares C, Talucod J, Press CJ, Montoya JG. Significance of a Positive Toxoplasma Immunoglobulin $M$ Test Result in the United States. J Clin Microbiol. 2015 Nov;53(11):3601-5. doi: 10.1128/ JCM.01663-15.

18. Del Bono V, Canessa A, Bruzzi P, Fiorelli MA, Terragna A. 1989. Significance of specific immunoglobulin $M$ in the chronological diagnosis of 38 cases of toxoplasmic lymphadenopathy. J Clin Microbiol 27:2133-2135.

19. Gras L, Gilbert RE, Wallon M, Peyron F, Cortina-Borja M. 2004. Duration of the IgM response in women acquiring Toxoplasma gondii during pregnancy: implications for clinical practice and cross-sectional incidence studies. Epidemiol Infect 132:541-548. doi:10.1017/S0950268803001948.

20. Roozbehani M, Gharavi MJ, Moradi M, Razmjou E. Detection of acute Toxoplasma gondii infection in pregnant women by $\operatorname{IgG}$ avidity and PCR analysis. Trop Biomed. 2018 Dec 1;35(4):908-914. PMID: 33601840.

21. Hampton MM. Congenital Toxoplasmosis: A Review. Neonatal Netw. 2015;34(5):274-8. doi: 10.1891/07300832.34.5.274. PMID: 26802827.

22. Naot Y, Remington JS. An enzyme-linked immunosorbent assay for detection of IgM antibodies to Toxoplasma gondii: use for diagnosis of acute acquired toxoplasmosis. J Infect Dis. 1980 Nov;142(5):757-66. doi: 10.1093/infdis/142.5.757. 23. Sarah YA, UzmaAK, Asmaa IE: Prevalence of seropositive toxoplasmosis in pregnant women in Hail region. Int J Health Sci Res. 2014, 4:66-71.

24. Mohajab AH, Alshehri HZ, Shati RO, Alshehri AA, Alafghani MA, Alasmari A, Almahi M, Oraif A. Antitoxoplasma Antibody Prevalence and Cost-effectiveness in Pregnant Women at the King Abdulaziz University Hospital, Jeddah, Saudi Arabia. Cureus. 2020 Jan 16;12(1):e6675. doi: 10.7759/cureus.6675.

25. Alghamdi J, Elamin MH, Alhabib S: Prevalence and genotyping of Toxoplasma gondii among Saudi pregnant women in Saudi Arabia. Saudi Pharm J. 2016, 24:645-51. 10.1016/j.jsps.2015.05.001

26. Elsafi SH, Al-Mutairi WF, Al-Jubran KM, Abu Hassan MM, Al Zahrani EM. Toxoplasmosis seroprevalence in relation to knowledge and practice among pregnant women in Dhahran, Saudi Arabia. Pathog Glob Health. 2015;109(8):37782. doi: $10.1080 / 20477724.2015 .1103502$.

27. Aqeely H, El-Gayar EK, Perveen Khan D, Najmi A, Alvi A, Bani I, Mahfouz MS, Abdalla SE, Elhassan IM. Seroepidemiology of Toxoplasma gondii amongst Pregnant Women in Jazan Province, Saudi Arabia. J Trop Med. 
2014;2014:913950. doi: 10.1155/2014/913950.

28. Andiappan H, Nissapatorn V, Sawangjaroen N, Chemoh W, Lau YL, Kumar T, Onichandran S, Suwanrath C, Chandeying V. Toxoplasma infection in pregnant women: a current status in Songklanagarind hospital, southern Thailand. Parasit Vectors. 2014 May 22;7:239. doi: 10.1186/1756-33057-239.

29. Lin YL, Liao YS, Liao LR, Chen FN, Kuo HM, He S. Seroprevalence and sources of Toxoplasma infection among indigenous and immigrant pregnant women in Taiwan. Parasitol Res. 2008 Jun;103(1):67-74. doi: 10.1007/s00436008-0928-1.

30. Paul E, Kiwelu I, Mmbaga B, Nazareth R, Sabuni E, Maro A, Ndaro A, Halliday JEB, Chilongola J. Toxoplasma gondii seroprevalence among pregnant women attending antenatal clinic in Northern Tanzania. Trop Med Health. 2018 Nov 19;46:39. doi: 10.1186/s41182-018-0122-9.

31. Kieffer F, Wallon M. Congenital toxoplasmosis. Handb Clin Neurol. 2013;112:1099-1101. doi:10.1016/B978-0-44452910-7.00028-3.

32. Liu Q, Wei F, Gao S, Jiang L, Lian H, Yuan B, Yuan Z, Xia Z, Liu B, Xu X, Zhu XQ. Toxoplasma gondii infection in pregnant women in China. Trans R Soc Trop Med Hyg. 2009 Feb;103(2):162-6. doi: 10.1016/j.trstmh.2008.07.008.

33. Cong W, Dong XY, Meng QF, Zhou N, Wang XY, Huang SY, Zhu XQ, Qian AD. Toxoplasma gondii Infection in Pregnant Women: A Seroprevalence and Case-Control Study in Eastern China. Biomed Res Int. 2015;2015:170278. doi: 10.1155/2015/170278.

34. Gebremedhin EZ, Abebe AH, Tessema TS, Tullu KD, Medhin G, Vitale M, Di Marco V, Cox E, Dorny P. Seroepidemiology of Toxoplasma gondii infection in women of child-bearing age in central Ethiopia. BMC Infect Dis. 2013
Feb 26;13:101. doi: 10.1186/1471-2334-13-101.

35. Mwambe B, Mshana SE, Kidenya BR, Massinde AN, Mazigo HD, Michael D, Majinge C, Groß U. Seroprevalence and factors associated with Toxoplasma gondii infection among pregnant women attending antenatal care in Mwanza, Tanzania. Parasit Vectors. 2013 Aug 6;6:222. doi: 10.1186/1756-3305-6-222.

36. Makki SM, Abdel-Tawab AH. Anti-Toxoplasma gondii antibodies among volunteer blood donors in eastern Saudi Arabia. J Egypt Soc Parasitol. 2010 Aug;40(2):401-12. PMID: 21246947.

37. Obaid HM. Toxoplasma Sero-Prevalence and Related Knowledge Survey in Pregnant Women and University Staff. Int J Curr Microbiol App Sci. 2019;8(02):2808-2816. doi: 10.20546/ijcmas.2019.802.330

38. Abdalla Sayed Ahmed GM, Abo Elghite Elhossiny EE. Knowledge and Attitude of women regarding Toxoplasmosis during pregnancy and measures to overcome it in Slums areas. Int J Curr Res.2014;6(4):6365-71.

39. Onduru OG, Rumisha SF, Munyeme M, Phiri AM. Evaluation of the level of awareness of congenital toxoplasmosis and associated practices among pregnant women and health workers in Tanzania's Temeke district in Dar es Salaam. Afr Health Sci. 2019 Dec;19(4):3027-3037. doi: 10.4314/ahs.v19i4.24.

40. Desta AH. Knowledge, Attitude and Practice of community towards zoonotic importance of Toxoplasma infection in Central Afar Region, North East Ethiopia. Int J Biomed Sci Eng. 2015;3(6):74-86.

41. Ait Hamou S, Laboudi M. An analytical study on the awareness and practice relating toxoplasmosis among pregnant women in Casablanca, Morocco. BMC Public Health. 2021 Mar 16;21(1):507. doi: 10.1186/s12889-021-10474-9. 